\title{
Are HIV, HBV and HCV Voluntary Counseling and Testing Programs Needed in Balkans?
}

\author{
Camelia Sultana1,2, Ana-Maria Schweitzer³, Mihaela Bogdan³, Simona Ruta1,2 \\ ${ }^{1}$ Carol Davila University of Medicine and Pharmacy, Bucharest, Romania \\ ${ }^{2}$ Stefan S. Nicolau Virology Institute, Bucharest, Romania \\ 3Baylor Black Sea Foundation at Centrul Clinic de Excelenta, Spitalul Clinic de Boli Infectioase Constanta-Baylor College of Medicine -Texas Children's \\ Hospital- Abbott Fund-AbbVie Foundation, Constanta, Romania
}

To the Editor, Infections caused due to the HIV, HBV, and $\mathrm{HCV}$ are interrelated health conditions with similar behavioral determinants. In particular, Romania is significantly affected by these infections, with the largest pediatric HIV outbreak in Europe being reported during 1985-1992 (1), in addition to the significantly higher rates of chronic viral hepatitis infections than the European average (2). A free, communityrun voluntary counseling and testing program was conducted for patients with HIV and viral hepatitis during 2010-2014 in Dobrogea, Romania, a region with high levels of underdiagnosing and under-reporting (3). Informed consent was obtained from all patients, and the study was approved by the institutional IRBs. Serologic screening of 36.132 individuals for $\mathrm{HIV}, \mathrm{HBV}$, and $\mathrm{HCV}$ infections was carried out using rapid chromatographic tests, and reactive results were confirmed using immunological tests; all subjects filled in a self-reported assessment form regarding behavioral risk factors. Selfreferral was the most frequent point of entry into the program (76.9\%); people from rural areas were less likely to be referred by a healthcare professional for testing compared with those in urban areas $(26.2 \%$ vs. $32.6 \%, p=0.001)$. During the testing period, the mean prevalence rates of the three tested infections were found to be $0.4 \%$ for $\mathrm{HIV}, 3.2 \%$ for $\mathrm{HCV}$, and $4.4 \%$ for $\mathrm{HBV}$, with a linear ascending trend identified only for $\mathrm{HCV}$ prevalence (Table 1). The highest seroprevalence of HIV infection was observed in young persons (aged 20-39 years), whereas $\mathrm{HBV}$ and $\mathrm{HCV}$ infections were prevalent among elderly people (aged 50-59 years for HBV and more than 60 years for HCV). Our data suggest a high seroprevalence of unrecognized viral hepatitis infections in older people who were never screened and were exposed to potentially unsafe healthcare-associated parenteral practices before 1990-1995 (4). Although all the tested subjects received a 6-monthly retesting recommendation, retesting was performed for only $24 \%$ of the subjects; $0.2 \%$ of them were newly diagnosed with HIV (14 patients), 0.3\% were diagnosed with HBV (19 patients), and $0.8 \%$ were diagnosed with $\mathrm{HCV}$ (52 patients). The majority of subjects perceived themselves as having a history of medium- or high-risk exposure (78\%), with blood exposure and/or use of unsterilized equipment being more frequently recognized than sexual exposure (69\% vs. $26 \%$ of the cases, $\mathrm{p}=0.005)$. The reported drug use rate was also low $(0.08 \%)$, which can be expected in a self-referral or a general population screening program (5). Distribution of the self-assessed risks was similar among those tested once and those retested, with a significant association observed between the self-evaluated risk and the retesting probability $(\mathrm{p}<0.0001)$ and the strongest association observed with healthcare providers coming back for retesting $(\mathrm{p}<0.0001)$. These data suggest that programs aimed at strengthening the implementation of universal precautions in healthcare settings should be a priority. This voluntary counseling and testing program captures a cross-sectional image of health statuses and health-related behaviors of community members and provides important data for stakeholders for the design of a nationwide public health response to HIV and viral hepatitis. In Romania, as in other Balkan countries with a similar epidemiological background, there is a significant community demand for integrated health programs. Implementation of voluntary counseling and testing can complete the overall regional epidemiological picture and

Address for Correspondence: Dr. Camelia Sultana, Carol Davila University of Medicine and Pharmacy, Bucharest, Romania; Stefan S. Nicolau Virology Institute, Bucharest, Romania e-mail: camelia-sultana@yahoo.com_ＯRCID ID: orcid.org/0000-0002-5954-3312

Received: 15 September 2017 Accepted: 22 December 2017 • DOI: 10.4274/balkanmedj.2017.1229

Available at www.balkanmedicaljournal.org

Cite this article as:

Sultana C, Schweitzer AM, Bogdan M, Ruta S. Are HIV, HBV and HCV Voluntary Counseling and Testing Programs Needed in Balkans? Balkan Med J 2018;35:219-20

${ }^{\circ}$ Copyright 2018 by Trakya University Faculty of Medicine / The Balkan Medical Journal published by Galenos Publishing House. 
TABLE 1. Prevalence of infections and self-declared risk factors during the follow-up period

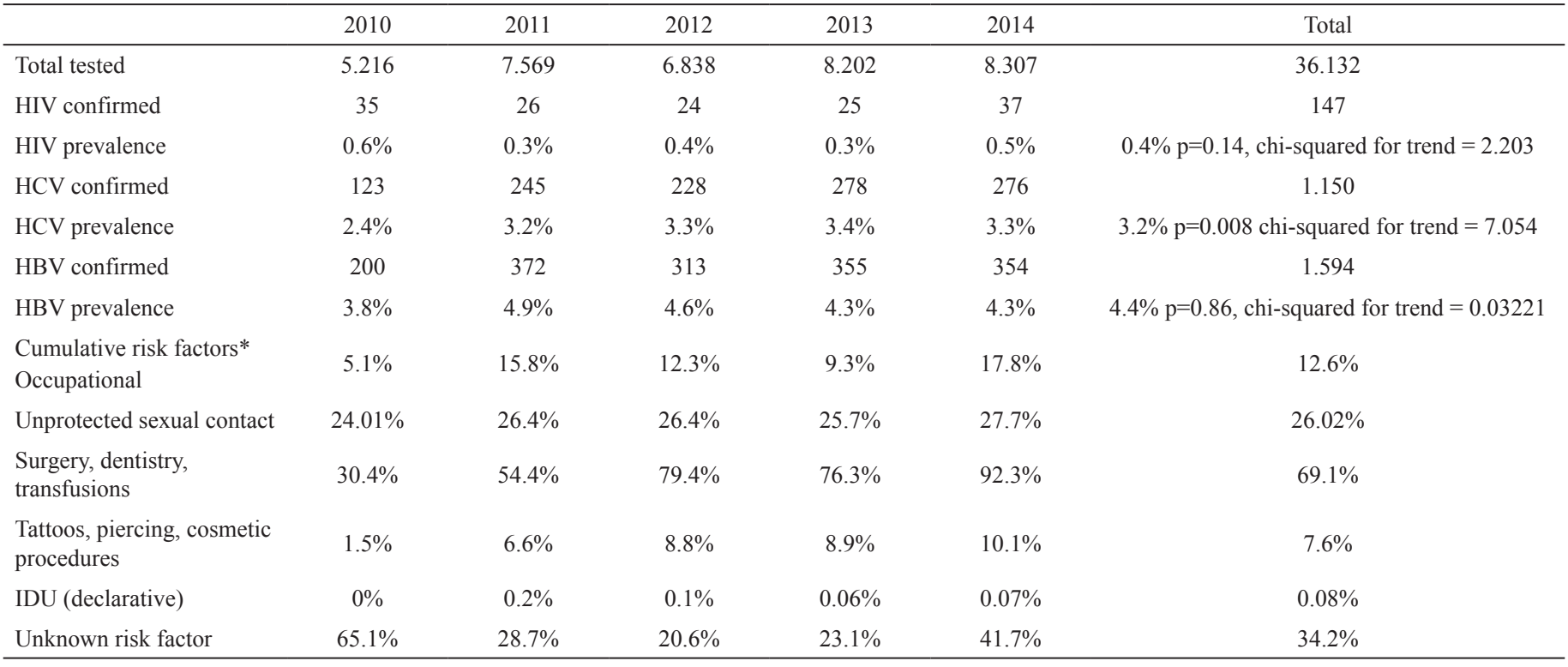

*Most of the patients presented more than one risk factor; HIV: human immunodeficiency virus; HCV: hepatitis C virus; IDU: injecting drug using; HBV: hepatitis B virus

concurrently raise awareness about the importance of early detection of infections.

Financial Disclosure: More than $80 \%$ of funding for this voluntary counseling and testing community program was available through grants from the Abbott Fund and the AbbVie Foundation philanthropic initiatives.

Conflict of Interest: No conflict of interest was declared by the authors.

\section{REFERENCES}

1. Ruta S, Cernescu C. Influence of social changes on the evolution of HIV infection in Romania. Int J Environ Stud 2008;65:501-13.
2. Oprea C, Ceausu E, Ruta S. Ongoing outbreak of multiple blood-borne infections in injecting drug users in Romania. Public Health 2013;127:1048-50.

3. Schweitzer AM, Bogdan M. Hepatitis C: Perspectives on Chronic Care in Constanta, Romania, Baylor Black Sea Foundation, 2015. Constanta. (cited 27 July 2017) Available at http://baylor.ro/wp-content/uploads/2015/06/studiu-hepatita-en. pdf

4. Sultana C, Erscoiu SM, Grancea C, Ceausu E, Ruta S. Predictors of Chronic Hepatitis C Evolution in HIV Co-Infected Patients From Romania. Hepat Mon 2013; $13: 8611$.

5. Henderson M. Values and preferences of people who inject drugs, and views of experts, activists and service providers: HIV prevention, harm reduction and related issues. World Health Organization 2014 (cited 9 November 2017). Available at: http:// apps.who.int/iris/bitstream/10665/128118/1/WHO-HIV-2014.20-eng.pdf 